\title{
Regarding AAP Guidance for School Re-Opening, An Open Letter to Dr. Goza
}

Julia Koehler, MD

Boston, July 5, 2020

Dear Dr. Goza,

I hope this message finds you well. Thank you so much for your tireless work for our Academy and on behalf of all children in this time of enormous challenges.

I am writing as the chair of the Immigrant Health Committee of the Massachusetts Chapter of the AAP, and as a Pediatric Infectious Disease specialist. I was also a founding member of the Immigrant Health Special Interest Group and a member of its national steering committee. I am writing today to respectfully express serious concerns around our Academy's document, "COVID-19 Planning Considerations: Guidance for School Re-entry. June 25, 2020" (Guidance).

\section{"I am writing today to respectfully express serious concerns around our Academy's document, "COVID-19 Planning Considerations: Guidance for School Re-entry. June 25, 2020" (Guidance)."}

My major concerns are:

1. That assumptions about SARS-CoV-2 infections in pediatric populations, for which evidence is insufficient at best, are stated as facts in this guidance;

2. That the guidance lacks consideration of the stark differences between schools in wealthy and in white school districts compared to those in poor, Black, Native American or immigrant communities; and

3. That the guidance was written without engaging other professionals in the schools, with whom we as pediatricians will do well to maintain a mutually informative, supportive, and respectful dialog.

This AAP Guidance has been used as the basis of a school reopening plan for Massachusetts that was published on 6/25/20. The Massachusetts school reopening plan raised alarm in immigrant communities and among teachers. Of this plan, a Black teacher said that she "feels that she and her colleagues are again being used as subjects in a Tuskegee-like experiment." I hope as an Academy we can reconsider and create a revised school reopening guidance more firmly based in scientific rigor, and that promotes racial justice by protecting the communities that have been hardest hit by COVID-19, (1) whose parents now fear that their children will be infected in school and will bring the virus home.

The physical presence of children in school is certainly a crucial goal. But achieving this goal at the expense of the protection of children, and by extension of their families and communities, from infection with SARS-CoV-2, will only further exacerbate the devastatingly unequal harm, by income, race, and ethnicity, that the pandemic has inflicted across the country. School districts in poor and in Black, Native American, and immigrant communities will most likely avail themselves of the justification provided by our Academy's Guidance to space desks as close as 3 feet together and to bring large numbers of students into single classrooms, thereby increasing the potential for viral transmission. 493 educators have already been laid off in Massachusetts in 3 under-resourced school districts alone, and the AAP Guidance will now be used to support holding classes with 30 or more students by the fewer remaining teachers. Educators in these classrooms will be placed at risk, while in wealthy towns parents will most likely ensure that students return to class only when physical distancing of at least 6 feet (as recommended by the CDC) and small class sizes of 10-15 students can be strictly adhered to - the strict adherence to a specific size of student groups that the guidance discourages.

A revised guidance document would include considerations delineated in the following.

Regarding concern \# 1, those assumptions about SARS-CoV-2 infections in pediatric populations, for which evidence is insufficient, are stated as facts: a low risk of infection and disease in children is claimed in the guidance. The experience of the last six months does, in fact, show that children are more likely to be asymptomatically infected and are much less likely to develop severe acute COVID-19 than adults. However, the consequences of asymptomatic infection of children, some of whom develop radiographic evidence of pneumonia, are not yet known. Concern for $\underline{\text { CNS sequelae of infections with endemic coronaviruses has }}$ been raised. (2) As we now know, a small number of SARS-CoV-2 infected children go on to develop a life-threatening inflammatory state, MIS-C, (3) whose long-term sequelae remain to be discovered. Also, as endemic coronaviruses often co-infect children with other respiratory viruses, (4) we do not yet know how co-infection with SARS-CoV-2 and viruses like influenza, metapneumovirus and RSV will impact children when school openings and the beginning of the cold season coincide.

Very rare complications like MIS-C and open questions about asyet-unknown long-term sequelae will be less relevant when viral transmission in the community is low. In school districts with high viral transmission, however, risk-benefit considerations will need to reflect a higher likelihood of rare events. A one-size-fits-all state- 
ment cannot reassure parents who want their children to learn and to be safe, and who are torn between their need to get back to work and fear of their child and their family being harmed by the coronavirus contracted in school.

The fact that children become infected with SARS-CoV-2 at substantial rates was underscored by one of the largest detailed studies from China with known index cases that introduced infections into families. Despite being one of the largest, this recent study (5) still comprises only 43 infected children $<14$ years of age among 314 families with children experiencing exposure to an index case. In this study, the incidence of infection in children exposed to an index case was $13 \%$ versus $21 \%$ in exposed adults; the infection rate of children hence was $60 \%$ that of adults, which cannot be dismissed as insignificant.

\section{"In this study, the incidence of infection in children exposed to an index case was $13 \%$ versus $21 \%$ in exposed adults; the infection rate of children hence was $60 \%$ that of adults, which cannot be dismissed as insignificant."}

Since daycare centers and schools were closed in jurisdictions experiencing significant COVID-19 outbreaks, the potential for children infected in these settings to bring SARS-CoV-2 into their families is not known. Large-scale studies investigating the likelihood of transmission from infected children to other children and adults are still lacking. Attempting to estimate the infectivity of children for their contacts, because of an impending government decision regarding reopening of schools, a prominent virology laboratory in Germany recently found that respiratory tract viral loads of children and adults did not differ; (6) previously, the same group had found that viral load detected by RT-PCR correlated with infectivity for tissue culture cells. (7) These workers concluded that children may be as infectious as adults to their contacts.

Concerningly, a research paper published in our Academy's jour-

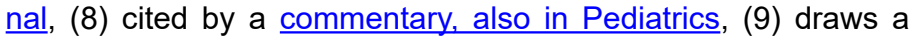
sweeping conclusion from very weak data. Specifically, the researchers, as well as the commentators, concluded that transmission rates of SARS-CoV2 from children to adults are low. This conclusion was based on findings of 39 COVID-19-symptomatic hospitalized children, whose family members were queried for the timing of COVID-19-symptom onset. In 3/39 children, all household members developed symptoms after the index child. This result was stated as "In only $8 \%$ (3/39) of households did the study child develop symptoms prior to any other HHC (household contact)." However, the report's Figure 1 shows that in another five children, adult household contacts became symptomatic simultaneously with or after the index children. Hence in total 8/39 $(20 \%)$ children's adult household contacts' symptoms began at the same time or after those of the index children. And in another six children, household pediatric siblings became symptomatic before the index children. The investigators did not state actual days of symptom onset relative to the index child cases; only "before, simultaneously and after" were recorded. It is known that the incubation period of COVID-19 can be substantially longer in children than in adults. One of the first reports on pediatric $\mathrm{CO}$ VID-19, (10) which appeared on 2/28/20, already noted a longer incubation period in children compared with adults. This observation was confirmed in subsequent investigations, most recently in Hua et al., (5) where children's COVID-19 incubation periods ranged from 5 to 21 days, with a mean of 9 days, i.e., $\sim 4$ days longer than the mean incubation time typically observed in adults. Hence conclusions on directionality of viral transmission between children and adults cannot be based on timing of symptom onset, especially when the information regarding this timing is as vague as in Posfay-Barbe et al. In other words, a girl who became symptomatic after her parent became sick may still have infected the parent during her asymptomatic incubation period. As recently noted in a Perspectives article in the journal Science, "infected individuals can be highly contagious for several days, peaking on or before symptoms occur." (11) It is estimated that $79 \%$ of $\mathrm{CO}$ VID-19 patients in Wuhan, whose infection was documented by testing, were infected by asymptomatic individuals with unknown infection status. (12)

Of note, as mentioned before, the SARS-CoV-2 transmission events examined by Posfay-Barbe et al. occurred during a time period in Geneva, Switzerland, when schools were closed. Even disregarding its small sample size and failure of the investigators to record symptom onset days of the study subjects, the setting of this study precludes simple extrapolation of its findings to communities in which schools are open.

The statement in the guidance (p.2), "children may be less likely to become infected and to spread infection," hence is insufficiently supported by the available data. Similarly, the statement "evidence suggests that spacing as close as 3 feet may approach the benefits of 6 feet of space, particularly if students are wearing face coverings and are asymptomatic" (p. 2 of the guidance) marshals thin theoretical considerations alone, but has no basis in epidemiological studies: such studies do not exist.

The statement, "infection via aerosols and fomites is less likely," (p. 4 of the guidance) is not accurate, and equating these two

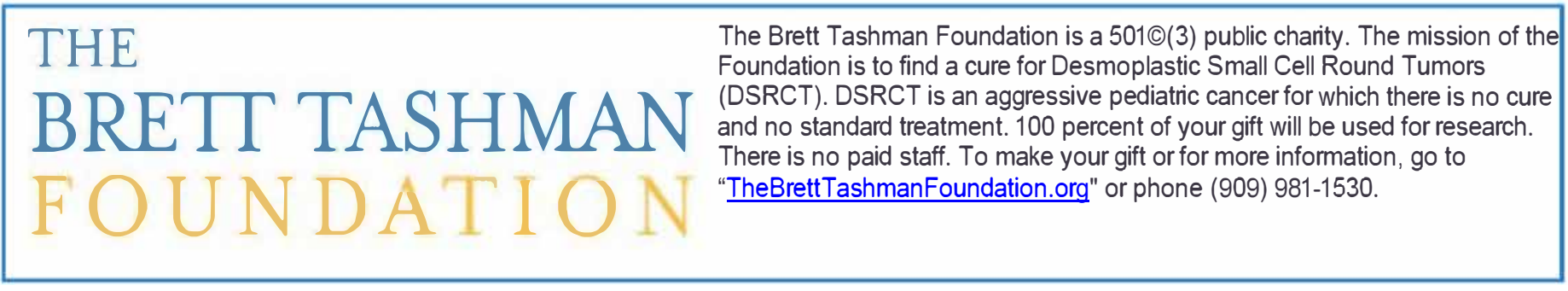


modes of transmission generates confusion. Infection via fomites has, in fact, not been demonstrated convincingly, though its theoretical risk is the basis for the ubiquitous and appropriately cautionary, exhortations for hand washing, as well as the mandate to sanitize surfaces in the guidance. In contrast, there is a large body of evidence supporting viral transmission via aerosols. (13) Aerosol transmission is highly significant, according to many researchers, like the authors of a recent epidemiologic study published by Proceedings of the National Academy of Sciences entitled "Identifying airborne transmission as the dominant route for the spread of COVID-19". (14) This point has been stated for scientific as well as lay audiences for months. (11)

The consensus around airborne transmission of SARS-CoV-2 that is now accepted among nationally recognized Infectious Disease experts is reflected in their responses to interview questions like that published $7 / 3 / 20$ in the Washington Post, e.g. Dr. Anthony Fauci's of the NIAID and Dr. Elizabeth Connick's of University of Arizona responses regarding eating in restaurants: "Fauci: We don't do anything inside. I don't eat in restaurants. (15) We do get takeout. Connick: No, no restaurants. I avoid any closed space with a lot of people, particularly when it's people whose risk I don't know. I think the biggest risk is being in a closed space and breathing the same air that other people are breathing, and also not wearing masks. I wouldn't go even if they were wearing masks."

Similarly, standard expert advice regarding social gatherings, as in a $7 / 3 / 20$ article in the New York Times, emphasizes that outdoor gatherings are much safer than those held indoors. (16) This would make no sense if aerosol transmission did not play a significant role in SARS-CoV-2 infection, since aerosols containing SARS-CoV-2 are quickly diluted by air currents outdoors, but indoors can build up to high densities over time.

The significant risk of aerosol transmission from asymptomatically infected children or school staff should also inform the revision of statements like "strict adherence to a specific size of student groups (eg, 10 per classroom, 15 per classroom, etc) should be discouraged" (p.2, Guidance) and "the risk reduction of reducing class sizes in elementary school-aged children may be outweighed by the challenge of doing so" (p.3, Guidance). Limiting student group sizes while keeping classrooms well ventilated through open windows and doors, in fact, can play a possibly significant role in risk reduction. The challenge of doing so is posed by the stark resource deprivations from which poor school districts suffer. These deprivations are due only to political decisions that have normalized structural racism and class-based withholding of educational resources. Accepting them as given legitimizes not only the educational losses that millions of children in this country suffer but now may even force these children and their families to accept an increased infection risk with SARS-CoV-2 as the price for going to school at all.

Regarding concern \# 2, that the guidance lacks consideration of the stark differences between schools in wealthy and in white school districts compared to those in poor, Black, Native American or immigrant communities, the guidance itself cites "growing concerns about systemic racial inequity" (p. 9). Hence as an Academy, we would do well to guard against implicitly facilitating harsh further systemic racial inequity by which some children will be far less protected from infection than others. As Dr. Martin Luther King said, "Of all the forms of inequality, injustice in health is the most shocking and the most inhuman." (17) Justifying less safe school environments for poor, Black, Native American, and immigrant children by setting a bar that is significantly lower than precautions that high-income white school districts and their parents will likely enforce inflicts an injustice in health that I am certain runs counter to the intentions of the Academy.

Regarding concern \# 3, we as pediatricians would do well to include the professionals that work in schools impacted by the Academy's Guidance in the conversation and to establish respectful and mutually informative dialogs. Pediatricians' own children are unlikely to attend the under-resourced schools whose further deprivation this guidance may be used to justify. Lacking first-hand information, we may easily overlook the facts on the ground that require advocacy for drastically improving resources for these schools, including the higher staff-to-student ratio required for safe school environments in the pandemic. Teachers, school nurses, and other educators must be our partners in the endeavor to create a protective and fruitful educational environment for all students. Of note, their children are our patients too and will suffer if their parents become ill with COVID-19. In this way, we can contribute to the work to relieve the harsh neglect and starvation for resources that poor Black, Native American, and immigrant school children have suffered unrelentingly over the past century.

Detailed guidance on how schools can be made safer for students and staff, acknowledging that COVID-19 transmission risk can never be completely eliminated, is available from multiple sources, e.g., in the June 5 publication of the Harvard School of Public Health "Schools for Health: Risk Reduction Strategies for Reopening Schools" (available at https://schools.forhealth.org/ wp-content/uploads/sites/19/2020/06/Harvard-Healthy-BuildingsProgram-Schools-For-Health-Reopening-Covid19-June2020. pdf). (18) Making schools safer for all children will not be possible in many communities with current funding formulas. Now is the time to invest in schools, their buildings, and their staff, contributing to remedy the deeply unjust underfunding of so many children's education while addressing the employment losses that are

\section{"Now is the time to invest in schools, their buildings, and their staff, contributing to remedy the deeply unjust underfunding of so many children's education while addressing the employment losses that are devastating the nation."}

devastating the nation.

In summary, the truly crucial goal that students attend classes in person would best not be pursued by providing justification for conditions in schools that run counter to CDC recommendations, scientific evidence or consensus of nationally respected Infectious Disease experts and that parents in wealthy school districts are 
unlikely to accept. Let us not accept lower safety standards that can be unjustly imposed on the communities already hardest hit by COVID-19. Scientific rigor ought not to be sacrificed in pursuit of expediency along the path of least resistance. Cautious school reopening accompanied by a simultaneous collection of data, and readiness to modify practices in response to research results, will best satisfy both the need for children to be present in school and their right to stay safe. As pediatricians, let us start with the best interests, health, and well-being of all children and continue to advocate until their needs are met, partnering with other professionals that share our goals. If this requires confronting entrenched systemic racism and class-based deprivation, we as pediatricians can muster the moral courage to do so, since we are tasked with

"As pediatricians, let us start with the best interests, health, and well-being of all children and continue to advocate until their needs are met, partnering with other professionals that share our goals. If this requires confronting entrenched systemic racism and classbased deprivation, we as pediatricians can muster the moral courage to do so, since we are tasked with standing up for the rising generations."

standing up for the rising generations.

Based on these considerations, I respectfully ask the appropriate bodies of our Academy to reconsider the document "COVID-19 Planning Considerations: Guidance for School Re-entry. June 25, 2020." In the meantime, I will ask my chapter to withdraw the endorsement of the Massachusetts guidelines based on this document. Please consider this an open letter as I intend to share it broadly with others for whom these issues may be relevant.

Thank you very much in advance for your consideration of this message. I look forward to hearing from you.

Sincerely,

Julia Koehler, MD

Associate Physician in Pediatrics

Division of Infectious Disease, Boston Children's Hospital

Assistant Professor of Pediatrics, Harvard Medical School

\section{References:}

1. https://www.nytimes.com/interactive/2020/07/05/ us/coronavirus-latinos-african-americanscdc-data.html? action =click\&module $=$ Top $\% 20$ Stories\&pgtype $=$ Homepage

2. Lau SK, Woo PC, Yip CC, et al. Coronavirus HKU1 and other coronavirus infections in Hong Kong. J Clin Microbiol.
2006;44(6):2063-2071. doi:10.1128/JCM.02614-05

3. https://www.cdc.gov/coronavirus/2019-ncov/daily-life-coping/ children/mis-c.html

4. Principi N, Bosis S, Esposito S. Effects of coronavirus infections in children. Emerg Infect Dis. 2010 Feb;16(2):1838. doi: 10.3201/eid1602.090469. PMID: 20113545; PMCID: PMC2957994.

5. Hua, CZ, Miao, ZP, Zheng, JS, et al. Epidemiological features and viral shedding in children with SARS-CoV-2 infection. J Med Virol. 2020; 1- 9. https://doi.org/10.1002/jmv.26180

6. Jones TC, Mühlemann B, Veith T, Biele G, Zuchowski M, Hoffmann J, et al. An analysis of SARS-CoV-2 viral load by patient age. medRxiv. 2020:2020.06.08.20125484. doi: 10.1101/2020.06.08.20125484.

7. Wölfel R, Corman VM, Guggemos W, Seilmaier M, Zange $S$, Müller MA, Niemeyer D, Jones TC, Vollmar $P$, Rothe $C$, Hoelscher M, Bleicker T, Brünink S, Schneider J, Ehmann $R$, Zwirglmaier $K$, Drosten C, Wendtner C. Virological assessment of hospitalized patients with COVID-2019. Nature. 2020 May;581(7809):465-469. doi: 10.1038/s41586020-2196-x. Epub 2020 Apr 1. PMID: 32235945.

8. Posfay-Barbe KM, WagnerN, Gauthey M, Moussaoui D, Loevy $N$, Diana A, et al. COVID-19 in Children and the Dynamics of Infection in Families. Pediatrics. 2020:e20201576. doi: 10.1542/peds. 2020-1576.

9. Lee B, Raszka WV. COVID-19 Transmission and Children: The Child Is Not to Blame. Pediatrics. 2020:e2020004879. doi: 10.1542/peds.2020-004879.

10. Jiehao C, Jin X, Daojiong L, Zhi Y, Lei X, Zhenghai $Q$, et al. A Case Series of Children With 2019 Novel Coronavirus Infection: Clinical and Epidemiological Features. Clinical Infectious Diseases. 2020. doi: 10.1093/cid/ciaa198.

11. Prather KA, Wang CC, Schooley RT. Reducing transmission of SARS-CoV-2. Science. 2020;368(6498):1422-4. doi: 10.1126/science.abc6197.

12. Asadi S, Bouvier N, Wexler AS, Ristenpart WD. The coronavirus pandemic and aerosols: Does COVID-19 transmit via expiratory particles? Aerosol Science and Technology. 2020;54(6):635-8. doi: 10.1080/02786826.2020.1749229.

13. https://www.nytimes.com/2020/07/04/health/239experts-with-1-big-claim-the-coronavirus-isairborne.html? action =click \& module $=$ Top $\% 20$ Stories\&pgtype $=$ Homepage

14. Zhang R, Li Y, Zhang AL, Wang Y, Molina MJ. Identifying airborne transmission as the dominant route for the spread of COVID-19. Proceedings of the National Academy of Sciences. 2020;117(26):14857-63. doi: 10.1073/pnas. 2009637117.

15. https://www.washingtonpost.com/health/how-fauci-5-otherhealth-specialists-deal-with-covid-19-risks-in-their-everydaylives/2020/07/02/d4665ed6-b6fb-11ea-a510-55bf26485c93 story.html

16. https://www. nytimes.com/2020/07/03/well/livel coronavirus-spread-outdoors-party.html? surface $=$ mostpopular\&fellback $=$ false\&req $i d=155218542 \&$ algo $=$ top conversion \&imp id $=370556679 \&$ action $=$ click $\&$ module $=M o$ st\%20Popular\&pgtype $=$ Homepage

17. https://muse.jhu.edu/article/686948/pdf

18. https://schools. forhealth.org/wp-content/uploads/ sites/19/2020/06/Harvard-Healthy-Buildings-ProgramSchools-For-Health-Reopening-Covid19-June2020.pdf 
The author has no conflicts to disclose

NT
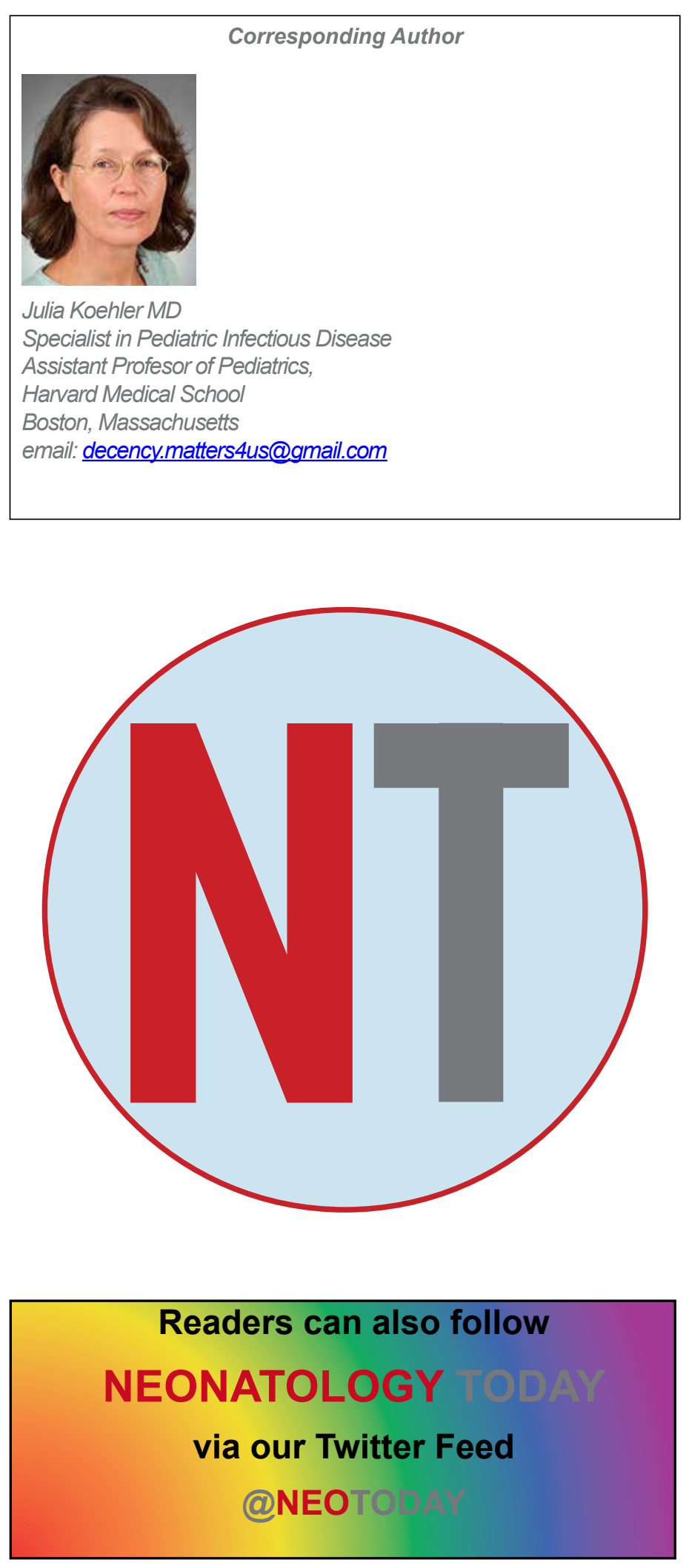

\section{OPIOIDS and NAS}

When reporting on mothers, babies, and substance use

\section{LANGUAGE MATTERS}
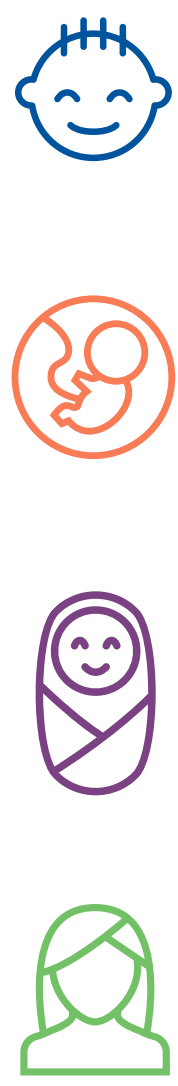

My mother may have a SUD.

She might be receiving Medication-Assisted Treatment (MAT). My NAS may be a side effect of her appropriate medical care. It is not evidence of abuse or mistreatment.

\section{My potential is limitless.}

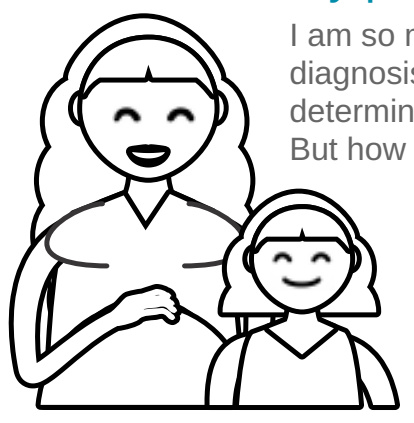

mo more than my NAS sis. My drug exposure will not determine my long-term outcomes. ut how you treat me will. When you invest in my family's health and wellbeing by supporting Medicaid and Early Childhood Education you can expect that I will do as well as any of my peers!

Learn more about

Neonatal Abstinence Syndrome at www.nationalperinatal.org 